\title{
Pilar Sheath Acanthoma
}

National Cancer Institute

\section{Source}

National Cancer Institute. Pilar Sheath Acanthoma. NCI Thesaurus. Code C4468.

A benign, small, papular or nodular skin neoplasm that usually arises above the upper lip.

It is characterized by an epithelial proliferation with a central cavity. The cavity wall is lined with keratinocytes. 